\title{
REDESAIN WADUK KLAMPIS KECAMATAN KEDUNGDUNG KABUPATEN SAMPANG SEBAGAI BANGUNAN PEMBANGKIT TENAGA AIR
}

\author{
Achmad Agung, Nadjadji Anwar, dan Danayanti Azmi Dewi Nusantara \\ Jurusan Teknik Sipil, Fakultas Teknik Sipil dan Perencanaan, Institut Teknologi Sepuluh Nopember (ITS) \\ Email :achmad,agung006@gmail.com, Nadjadji@ce.its.ac.id, azmidewi@gmail.com
}

\begin{abstract}
Abstrak - Pembangkit Listrik Tenaga Air (PLTA) merupakan pembangkit listrik yang mengandalkan energi potensial dan kinetik dari air. Pembangkit Listrik Tenaga Air (PLTA).Waduk klampis yang terletak di Desa Kramat Kecamatan Kedungdung Kabupaten Sampang merupakan waduk yang memiliki pontesi besar untuk dijadikan pembangkit listrik tenaga air. Permasalahan utama yang dihadapi Waduk Klampis adalah semula waduk klampis di gunakan untuk mencukupi kebutuhan irigasi, sekarang akan direncanakan pembangkit listrik tenaga air. Dengan meninggikan tinggi mercu hingga di +35 agar kapasitas waduk lebih besar dan efektif. Untuk mengetahui debit yang akan digunakan agar kebutuhan irigasi dan pembangkit listrik tenaga air berjalan seimbang maka di perlukan analisa debit inflow dan outflow. Dari hasil analisa diperoleh debit banjir rencana periode ulang 1000 tahun sebesar $1098,098 \mathrm{~m}^{3} /$ detik, volume efektif tertampung $15.302 .727,00 \mathrm{~m}^{3}$, debit outflow yang melimpah di atas mercu sebesar $526.89 \mathrm{~m}^{3} /$ detik. Mercu di desain dengan lebar $50 \mathrm{~m}$ dengan tinggi air sebesar $2.84 \mathrm{~m}$ dan panjang spillway $12,5305 \mathrm{~m}$. Debit inflow dari metode FJ. Mock $2.42 \mathrm{~m}^{3} / /$ detik total setahun. Debit irigasi sebesar $26,745 \mathrm{~m}^{3} /$ detik dalam setahun.

Dengan mengunakan metode simulasi direncanakan 2 buah turbin dengan debit 1.1 $\mathrm{m}^{3} /$ detik/turbin yang digunakan untuk pembangkit listrik tenaga air, didapat dimensi intake $2 \mathbf{m ~} \mathrm{x}$ $2 \mathrm{~m}$, diameter pipa sebesar $79 \mathrm{~cm}$ dengan tebal $4 \mathrm{~mm}$ dan dimensi saluran pembuang lebar $1.5 \mathrm{~m}$ tinggi air $0.9 \mathrm{~m}$, dari hasil perencanaan pembangkit listrik didapat energi listrik yang di hasilkan sebesar 1.259.757 KwH dalam setahun.
\end{abstract}

Kata Kunci - PLTA, Waduk Klampis

\section{PENDAHULUAN}

Pembangkit Listrik Tenaga Air (PLTA) merupakan pembangkit listrik yang mengandalkan energi potensial dan kinetik dari air. Pembangkit Listrik Tenaga Air (PLTA) sekarang masih menyediahkan $20 \%$ listrik di dunia

Atas dasar hal tersebut, manusia telah berupaya membangun Pembangkit Listrik Tenaga Air (PLTA) untuk mencukupi kebutuhan sehari-harinya.

Waduk klampis yang berada di kecamatan kedungdung kabupaten Sampang Madura. Waduk klampis yang dahulu di gunakan sebagai irigasi sekarang di modifikasi agar bisa menjadi Pembangkit Listrik Tenaga Air

Dengan debit waduk secara existing dan hasil analisa diharapkan mampu untuk memenuhi pembangunan Pembangkit Listrik Tenaga Air (PLTA) dengan skala besar tanpa menganggu kebutuhan irigasi yang ada di kecamatan kedungdung kabupaten Sampang

Madura.

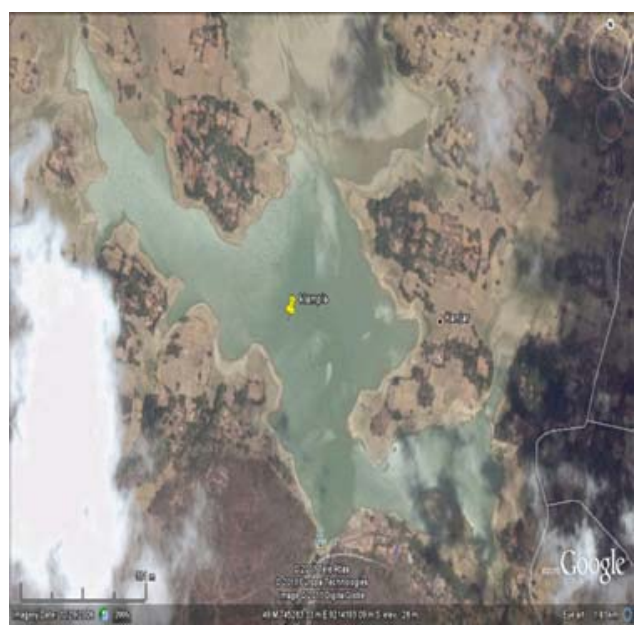

Gambar 1. Lokasi Genangan Waduk Klampis 


\section{METODOLOGI}

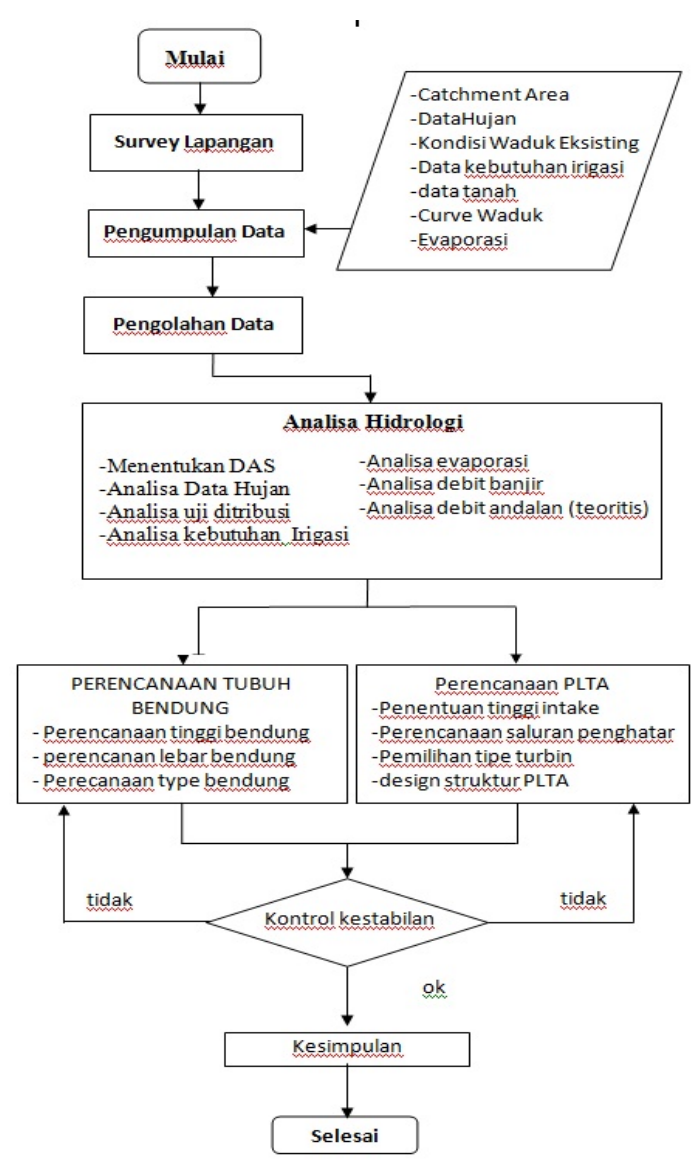

Gambar 2. Diagram Chart Metodologi

\section{HASIL DAN ANALISA}

\subsection{Distribusi Hujan}

Distribusi probabilitas terdiri dari 4 metode,

1. Distribusi Normal

2. Ditribusi log normal

3. Distribusi gumbel

4. Distribusi log pearson type III

\section{Tabel 1. Hasil Perhitungan Distribusi Hujan dengan berbagai metode.}

\begin{tabular}{|c|c|c|c|c|c|c|}
\hline No & $\begin{array}{c}\text { Periode } \\
\text { Ulang }(\mathrm{Tr})\end{array}$ & $\begin{array}{c}\text { Kemungkinan } \\
\text { Terjadi }(\%) \\
\mathrm{P}(\mathrm{X})=\left(\frac{(}{\pi r}\right) \times 100\end{array}$ & $\begin{array}{c}\text { Distribusi } \\
\text { Normal } \\
(\mathrm{mm})\end{array}$ & $\begin{array}{c}\text { Distribusi } \\
\text { Log Normal } \\
(\mathrm{mm})\end{array}$ & $\begin{array}{c}\text { Distribusi } \\
\text { Gumbel } \\
(\mathrm{mm})\end{array}$ & $\begin{array}{c}\text { Distribusi } \\
\text { Log Pearson } \\
\text { Tipe III }\end{array}$ \\
\hline 1 & 2 & 3 & 4 & 5 & 6 & 7 \\
\hline 1 & 1 & 100.00 & & 20.9247 & & 34.6148 \\
2 & 1.11 & 90.09 & 31.40 & 38.2523 & 28.90 & 40.3712 \\
3 & 2 & 50.00 & 62.63 & 59.1731 & 38.03 & 55.8935 \\
4 & 5 & 20.00 & 83.13 & 78.7884 & 59.28 & 76.5577 \\
5 & 10 & 10.00 & 93.87 & 91.5359 & 66.98 & 93.4337 \\
6 & 20 & 5.00 & 102.65 & 103.4854 & 76.00 & \\
7 & 25 & 4.00 & & & & 118.9307 \\
8 & 50 & 2.00 & 112.66 & 119.0057 & 148.44 & 141.1679 \\
9 & 100 & 1.00 & 119.49 & 130.9224 & 166.05 & 166.5047 \\
10 & 1000 & 0.10 & 138.04 & 169.6329 & 224.23 & 280.9067 \\
\hline
\end{tabular}

\subsection{Uji Distribusi}

Pengujian parameter yang dilakukan adalah :

a. Smirnov Kolmogorov

b. Chi-Kuadrat (Chi-Square)

Tabel 2. Hasil Pengujian Metode Uji

\section{Chi-Kuadrat}

\begin{tabular}{|l|c|c|l|}
\hline \multicolumn{1}{|c|}{ Analis a Dis tribusi } & $\begin{array}{c}\text { Chi } \\
\text { Kuadrat }\end{array}$ & $\begin{array}{c}\text { Chi Kuadrat } \\
\text { Kritis }\left(\mathbf{X}^{2} \mathbf{C r}\right)\end{array}$ & \multicolumn{1}{|c|}{ Kesimpulan } \\
\hline Distribusi Normal & 1 & 3.841 & Perhitungan dapat diterima \\
Distribusi Gumbel & 3.182 & 5.991 & Perhitungan dapat diterima \\
Distribusi Log Normal & 1 & 3.841 & Perhitungan dapat diterima \\
Distribusi Log Pearson III & 1 & 5.991 & Perhitungan dapat diterima \\
\hline
\end{tabular}

Tabel 3. Hasil Pengujian Metode Uji Smirnov-Kolmogorov

\begin{tabular}{|l|c|c|l|}
\hline \multicolumn{1}{|c|}{ Analis a Dis tribusi } & D Maks & $\Delta$ Kritis & Kesimpulan \\
\hline Distribusi Normal & 0.067 & 0.398 & Perhitungan dapat diterima \\
Distribusi Gumbel & 0.166 & 0.398 & Perhitungan dapat diterima \\
Distribusi Log Normal & 0.107 & 0.398 & Perhitungan dapat diterima \\
Distribusi Log Pearson III & 0.131 & 0.398 & Perhitungan dapat diterima \\
\hline
\end{tabular}

\subsection{Perhitungan curah hujan efektif}

Rumus yang digunakan

Reff $=\mathrm{C} \times \mathrm{Xt}$

Dimana :

Reff = curah hujan effektif

$\mathrm{C} \quad=$ koefisien pengalir

$\mathrm{Xt}=$ Curah hujan rencana

Pada lokasi waduk termasuk daerah bergelombang dan hutan, maka diambil koefisien pengaliran 0.75 dengan curah hujan terpusat di Indonesia selama 5 jam

\subsection{Debit Banjir Nakayasu}

Perhitungan debit banjir menggunakan metode pemodelan hujan - debit yang dikembangkan oleh Nakayasu. Dalam perhitungan menghasilkan gambar hidrograf seperti di bawah ini. 


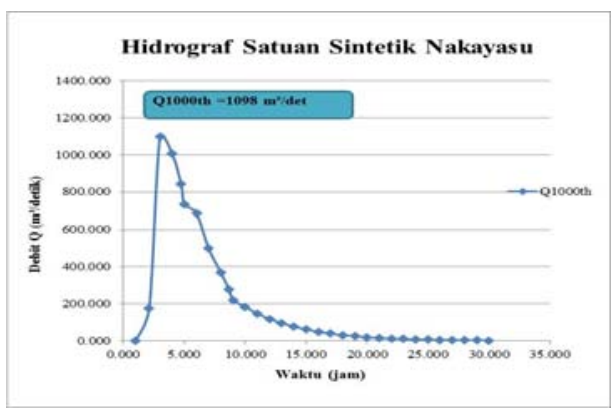

Gambar 3. HSS Nakayasu

Tabel 4. Peritungan HSS Nakayasu

\begin{tabular}{|c|c|c|c|c|c|c|c|}
\hline \multirow{2}{*}{$\mathbf{T}$} & \multirow{2}{*}{$U(t, 1)$} & \multicolumn{5}{|c|}{ Akibat Hujan } & \multirow{2}{*}{ Q1000 } \\
\hline & & $R 1(\mathrm{~mm})$ & $\mathrm{R2}(\mathrm{mm})$ & $\mathrm{R3}(\mathrm{mm})$ & $\mathbf{R 4}(\mathrm{mm})$ & $R 5(\mathrm{~mm})$ & \\
\hline (jam) & $\left(\mathrm{m}^{3} / \mathrm{det}\right)$ & 123.248 & \begin{tabular}{|l|}
32.023 \\
\end{tabular} & $22.543 \mid$ & 17.908 & 15.169 & $\left(\mathrm{~m}^{3} / \mathrm{det}\right)$ \\
\hline 0.000 & 0.000 & 0.000 & 0.000 & 0.000 & 0.000 & \begin{tabular}{l|l}
0.000 \\
\end{tabular} & 0.000 \\
\hline 1.000 & 1.421 & 175.098 & 0.000 & 0.000 & 0.000 & 0.000 & 175.098 \\
\hline 2.111 & 8.541 & 1052.650 & 45.495 & 0.000 & 0.000 & 0.000 & 1098.146 \\
\hline 3.000 & 5.680 & 700.095 & 273.509 & 32.026 & 0.000 & 0.000 & 1005.631 \\
\hline 4.000 & 3.589 & 442.393 & 181.905 & 192.536 & 25.442 & 0.000 & 842.276 \\
\hline 4.734 & 2.562 & 315.795 & 114.947 & 128.052 & 152.949 & 21.550 & 733.293 \\
\hline 5.000 & 2.362 & 291.145 & 82.053 & 80.916 & 101.723 & 129.557 & 685.394 \\
\hline 6.000 & 1.740 & 214.393 & 75.648 & 57.761 & 64.279 & 86.166 & 498.246 \\
\hline 7.000 & 1.281 & 157.874 & 55.705 & 53.252 & 45.885 & 54.448 & 367.165 \\
\hline 8.000 & 0.943 & 116.255 & 41.020 & 39.214 & 42.303 & 38.867 & 277.659 \\
\hline 8.669 & 0.769 & 94.739 & 30.206 & 28.876 & 31.151 & 35.833 & 220.805 \\
\hline 9.000 & 0.712 & 87.804 & 24.616 & 21.264 & 22.939 & 26.387 & 183.010 \\
\hline 10.000 & 0.566 & 69.798 & 22.814 & 17.328 & 16.892 & 19.431 & 146.263 \\
\hline 11.000 & 0.450 & 55.484 & 18.136 & 16.060 & 13.765 & 14.308 & 117.753 \\
\hline 12.000 & 0.358 & 44.106 & 14.416 & 12.766 & 12.758 & 11.660 & 95.706 \\
\hline 13.000 & 0.284 & 35.061 & 11.460 & 10.148 & 10.142 & 10.807 & 77.617 \\
\hline 14.000 & 0.226 & 27.871 & 9.110 & 8.067 & 8.062 & 8.591 & 61.700 \\
\hline 15.000 & 0.180 & 22.155 & 7.242 & 6.413 & 6.409 & 6.829 & 49.047 \\
\hline 16.000 & 0.143 & 17.612 & 5.757 & 5.098 & 5.094 & 5.428 & 38.988 \\
\hline 17.000 & 0.114 & 14.000 & 4.576 & 4.052 & 4.050 & 4.315 & 30.993 \\
\hline 18.000 & 0.090 & 11.129 & 3.638 & 3.221 & 3.219 & 3.430 & 24.637 \\
\hline 19.000 & 0.072 & 8.847 & 2.892 & 2.561 & 2.559 & 2.727 & 19.585 \\
\hline 20.000 & 0.057 & 7.032 & 2.299 & 2.036 & 2.034 & 2.168 & 15.568 \\
\hline 21.000 & 0.045 & 5.590 & 1.827 & 1.618 & 1.617 & 1.723 & 12.376 \\
\hline 22.000 & 0.036 & 4.444 & 1.452 & 1.286 & 1.285 & 1.370 & 9.838 \\
\hline 23.000 & 0.029 & 3.532 & 1.155 & $\begin{array}{l}1.022 \\
\end{array}$ & 1.022 & $\begin{array}{l}1.089 \\
\end{array}$ & 7.820 \\
\hline 24.000 & 0.023 & 2.808 & 0.918 & 0.813 & 0.812 & 0.866 & 6.216 \\
\hline 25.000 & 0.018 & 2.232 & 0.730 & 0.646 & 0.646 & 0.688 & 4.942 \\
\hline 26.000 & 0.014 & 1.774 & 0.580 & 0.514 & 0.513 & 0.547 & 3.928 \\
\hline 27.000 & 0.011 & 1.411 & 0.461 & 0.408 & 0.408 & 0.435 & 3.123 \\
\hline 28.000 & 0.009 & 1.121 & 0.366 & 0.325 & 0.324 & 0.346 & 2.482 \\
\hline 29.000 & 0.007 & 0.891 & 0.291 & 0.258 & 0.258 & 0.275 & 1.973 \\
\hline 30.000 & 0.006 & 0.709 & 0.232 & 0.205 & 0.205 & 0.218 & 1.569 \\
\hline
\end{tabular}

\subsection{Kapasitas Efektif}

Kapasitas efektif dapat di lihat dari lengkung kapasitas. Dimana lengkung kapasitas adalah sebuah grafik yang menghubungkan luas genangan dengan volume tampungan terhadap elevasi
Tabel 5. Hasil perhitungan lengkung kapasitas waduk

\begin{tabular}{|c|c|c|c|c|}
\hline No & Kedalaman (m) & Luas Area $\left(m^{2}\right)$ & Volume $\left(m^{3}\right)$ & Vol. Komulatif $\left(\mathrm{m}^{3}\right)$ \\
\hline & 1 & 2 & 3 & 4 \\
\hline 1 & 2500 & $3006 . \infty$ & $0 . \infty$ & $\infty \infty$ \\
\hline 2 & 25.50 & 83878.83 & 21721.22 & 2172122 \\
\hline 3 & 2500 & 338623.83 & 10562569 & 127346.91 \\
\hline 4 & 26.50 & $\$ 0649283$ & 186279.19 & 313626.09 \\
\hline 5 & 2700 & $\mathbf{5 2 7 4 9 . 1 9}$ & 219510.52 & 533436.61 \\
\hline 6 & 27.50 & 547434.00 & 255045.80 & 78348241 \\
\hline 7 & 2800 & 522855.50 & 29257988 & 108105228 \\
\hline 8 & 28.50 & 20467300 & 331869.63 & 1412951.91 \\
\hline 9 & 2900 & 83311533 & 384477009 & 179739900 \\
\hline 10 & 29.50 & 92205213 & 436991.83 & 223539083 \\
\hline 11 & 30.00 & 1012757.06 & 48390230 & 2720293.17 \\
\hline 12 & 30.50 & 1206065269 & 555204.94 & 3275498.11 \\
\hline 13 & 3100 & 149519558 & 675514.64 & 395131275 \\
\hline 14 & 31.50 & 1727065.69 & 8055565.39 & 4756878.14 \\
\hline 15 & 3200 & 2291787.00 & 1004713.17 & 5761591.31 \\
\hline 16 & 3250 & 2820123994 & 078055273 & 703964105 \\
\hline 17 & 3300 & 307456200 & 1473746.48 & 8513390.53 \\
\hline 18 & 33.50 & 32956547000 & $15925552 \geq 5$ & 1010599278 \\
\hline 19 & 34.00 & 353318244 & 1732207.35 & 11835150.14 \\
\hline 20 & 3450 & 3656571113 & 2874738.39 & 1371268853 \\
\hline 21 & 3500 & 4153587.75 & 2004839.72 & 1571772825 \\
\hline 22 & 35.50 & 46125555.13 & 2240228.95 & 1795795720 \\
\hline 23 & 36.00 & 4949350.09 & 2111780.74 & 20369737.94 \\
\hline 24 & 36.50 & 5286614505 & 258333252 & 22395307046 \\
\hline $\mathbf{z}$ & 37.00 & 5622990.01 & Z51834_31 & 2570795477 \\
\hline 26 & 37.50 & 5959734.98 & 2926436.10 & 28534390.86 \\
\hline 27 & 36.00 & 62056529.94 & 3097987.68 & 31732378.75 \\
\hline 28 & 38.50 & 66333324.90 & 3269539.67 & 35001918.42 \\
\hline 29 & 39,00 & 6970119.86 & 341091.46 & 33443009.87 \\
\hline 30 & 39.50 & 7306914.83 & 3612643.24 & 420555653.11 \\
\hline 31 & 4000 & 764370979 & 38419503 & 45839848,14 \\
\hline
\end{tabular}

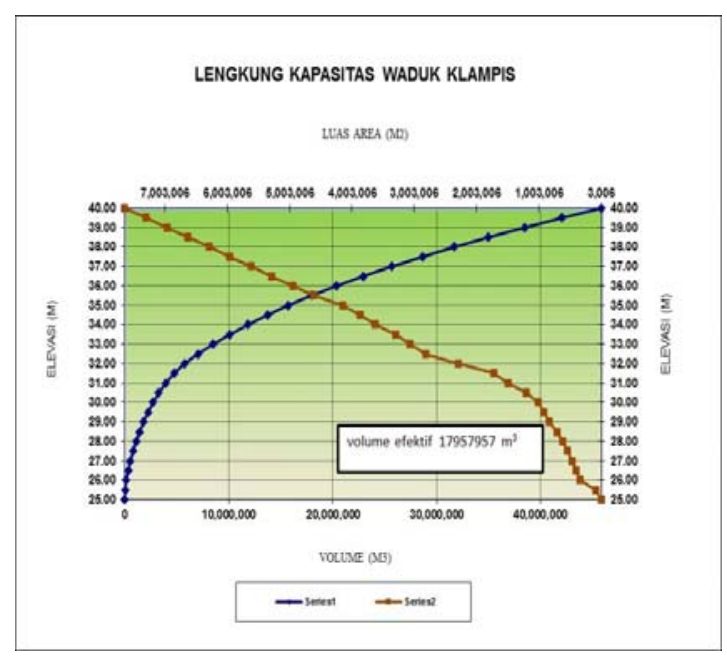

\section{Gambar 4. Lengkung Kapasitas Waduk}

\subsection{Penelusuran Banjir Waduk}

Penelusan banjir ini dimaksudkan agar dapat menganaliasa debit inflow dan outflow sehingga dapat mendapat tingi air diatas mercu secara efektif untuk merencanakan waduk yang sesuai dengan kriteria perencanaan bangunan air secara teknis 
Tabel 6. Hasil perhitungan flood routing

\begin{tabular}{|c|c|c|c|c|c|c|c|c|}
\hline No & $T$ & Inflow & $\frac{(1,+12)}{2}$ & $\psi$ & $\phi$ & $\mathrm{H}$ & Outflow & Elevas \\
\hline 1 & 0 & 0 & 0 & 0.00 & 0.00 & 0.00 & 200 & $35 \infty 0$ \\
\hline 2 & 1 & $17 \mathbf{2} 09762$ & 87.55 & & 87.55 & 0.10 & 474 & 3310 \\
\hline 3 & 2111 & 1098.1656 & 636.62 & 8281 & 719.43 & 0.5 & 7189 & $35 \pi$ \\
\hline 4 & 3 & 1005.6306 & 1051.89 & 647.55 & 1699.43 & 1.63 & 288.34 & $36 \sqrt{2} 3$ \\
\hline 5 & 4 & 84227606 & 923.95 & 1471.10 & 2356.05 & 220 & 358.87 & 37.20 \\
\hline 6 & 4.734 & 73329293 & 787.78 & 2036.18 & 2823.96 & 256 & 449.88 & 37.56 \\
\hline 7 & 5 & 68539385 & 708.34 & 2374.08 & 3083.42 & 277 & 507.66 & 37.77 \\
\hline 8 & 6 & \begin{tabular}{|l|}
498224616 \\
\end{tabular} & 591.82 & 257.7 & 318.59 & 284 & 526.89 & 37.84 \\
\hline g) & 7 & 367.16478 & 432.71 & 2640.70 & 307.41 & 276 & 565.41 & 37.76 \\
\hline 10 & 8 & \begin{tabular}{|l|}
27.65919 \\
\end{tabular} & 32241 & 266799 & 2890.40 & 2.61 & 464.39 & 37.61 \\
\hline 11 & 8.669 & 22080531 & 249.23 & 2426.02 & 265.25 & 243 & 417.67 & 37.43 \\
\hline 12 & 9 & 183.00976 & 201.91 & 225758 & 2459.49 & 225 & 372.32 & 37.25 \\
\hline 13 & 10 & 146.2627 & 164.64 & 2087.18 & 2251.81 & 2008 & 328.97 & 37.08 \\
\hline 14 & 11 & \begin{tabular}{|l|}
117.75326 \\
\end{tabular} & 13201 & 192284 & 2054.85 & 1.92 & 292.25 & 3692 \\
\hline 15 & 12 & 95.706473 & 106.73 & 176260 & 18 (19.33 & 177 & 258.26 & 3677 \\
\hline 16 & 13 & 77.61793 & 8266 & 1611.07 & 1697.74 & 1.63 & 228.04 & 3663 \\
\hline 17 & 14 & 61.6998 & 69.66 & 1469.70 & 1539.36 & 1.49 & 200.74 & 3649 \\
\hline 18 & 15 & $49.0466 \pi$ & 5537 & 13388,61 & 1398.99 & 1.37 & 176.04 & 36.37 \\
\hline 19 & 16 & 38.9854 & 4402 & 121794 & 1261.96 & 1.25 & 154.17 & 3625 \\
\hline 20 & 17 & 30.992831 & 3499 & 1107.79 & 114278 & 1.15 & 15.19 & 3615 \\
\hline z] & 18 & 24.626567| & 27.81 & 1007.59 & $105 \mathbf{5} .41$ & 105 & 118.55 & 3605 \\
\hline 22 & 19 & 19.584519 & 2211 & 916.86 & 938.97 & 0.96 & 104.05 & 3596 \\
\hline 23 & 20 & 15.568712 & 17.58 & 834.92 & 852.49 & 0.88 & 91.05 & 3588 \\
\hline 24 & 27 & 12.375861 & 1397 & 761.45 & $\mathbf{7 5 . 4 2}$ & 0.80 & 7946 & 3580 \\
\hline 25 & 22 & 9.8376277 & 1111 & (75.96 & 707.07 & 0.74 & 7023 & 3574 \\
\hline 26 & 23 & 7.8201703 & 883 & 636.83 & 646.66 & 0.68 & 6202 & 3568 \\
\hline 27 & 24 & 6.276A442 & 7.02 & 583.64 & 590.66 & 0.63 & 546 & 3563 \\
\hline 28 & $\mathbf{2 5}$ & 4.9416832 & 5.58 & 535.99 & 541.57 & 0.58 & 4844 & 3558 \\
\hline 20 & 26 & 3.9282009 & 443 & 93.13 & 497.56 & 0.53 & 4322 & 3553 \\
\hline 30 & 27 & 3.1226228 & $\mathbf{3 5 3}$ & 85.34 & 457.87 & 0.49 & 3851 & 3349 \\
\hline 31 & 28 & 2483249 & 280 & 41935 & 422.16 & 0.46 & 3428 & 3546 \\
\hline 32 & 29 & 19732003 & 223 & 387.88 & 390.11 & 0.42 & 3047 & 3542 \\
\hline 33 & 30 & 1.565651 & 177 & $\mathbf{3 9} 9.64$ & 361.41 & 0.39 & 27.27 & 3339 \\
\hline
\end{tabular}

\subsection{Perencanaan Spillway}

Saluran yang di gunakan untuk mengarahkan aliran air agar dalam kondisi hidrolis terbaik.

Direncanakan bendungan menggunakan pilar di atas mercu

Jumlah pilar (n): 7 buah

Ukuran pilar (L): 1 buah $3 \mathrm{~m}$ dan 6 buah $0.8 \mathrm{~m}$

Lebar efektif bendung

$$
\begin{aligned}
B_{\text {eff }} & =\mathrm{B} \text { bendung }-\Sigma(\mathrm{n} \times \mathrm{L}) \\
& =50 \mathrm{~m}-(1 \times 3 \mathrm{~m})-(6 \times 0.8) \\
& =42.2 \mathrm{~m}
\end{aligned}
$$

Maka tinggi muka air (h) akan lebih tinggi akibat pilar yang ada. perhitungan tinggi muka air (h) sebagai berikut :

$$
\begin{gathered}
\mathrm{Q}=\mathrm{CB}_{\text {eff }} \mathrm{h}^{3 / 2} \\
526.89 \mathrm{~m}^{3} / \mathrm{dtk}=2.2 \times 42.2 \times \mathrm{h}^{3 / 2} \\
\mathrm{~h}=2.84 \mathrm{~m}
\end{gathered}
$$

\subsection{Perhitungan Hidrolis di kaki spillway}

Direncanakan

lebar saluran transisi hilir $\left(\mathrm{b}_{2}\right)=12 \mathrm{~m}$

panjang saluran transisi $=12.5305 \mathrm{~m}$ dengan sudut $\theta=57^{0}$

beda tinggi $(\mathrm{z})=+35.00-17.00+3.949 \mathrm{~m}$

$$
=21.95 \mathrm{~m}
$$

Maka

$$
\begin{aligned}
& \mathrm{V}_{1}=\sqrt{2 \mathrm{~g}\left(\mathrm{z}-\frac{\mathrm{h}}{2}\right)} \\
& V_{1}=\sqrt{2 \times 9.8\left(21.95-\frac{2.84}{2}\right)} \\
& V_{1}=20.06 \mathrm{~m} / \mathrm{dtk} \\
& q=\frac{Q}{B_{2}}=q=\frac{526.89}{12} \\
& q=43.907 \mathrm{~m}^{2} / \mathrm{dtk} \\
& y_{u}=\frac{q}{v_{1}} \\
& y_{u}=\frac{43.9075 \mathrm{~m}^{2} / d t k}{20.06 \mathrm{~m} / \mathrm{dtk}}=2.19 \mathrm{~m} \\
& F=\frac{V_{1}}{\sqrt{g y u}} \\
& F=\frac{20.06}{\sqrt{9.82 .19}}=4.33
\end{aligned}
$$

\subsection{Bangunan Peredam Energy}

Peredam energi atau bisa disebut kolam olak di gunakan untuk meredamkan energi air agar terkontrol secara teknis.

Perencanaan bangunan peredam energi menggunakan USBR type IV dengan menggunakan persamaan :

$$
\begin{aligned}
& \frac{D_{1}}{D_{2}}=0.5(\sqrt{1+8 F}-1) \\
& \frac{D_{1}}{D_{2}}=0.5(\sqrt{1+8(3.6085)}-1)=2.68 \\
& \text { maka: } \\
& \mathrm{L}=5.2 \times 2.68=13.96 \mathrm{~m}
\end{aligned}
$$

\subsection{Evapotranspirasi metode Penma Modifikasi}

Perhitungan evapotranspirasi menggunakan metode modifikasi dari Penman, dengan hasil perhitungan sebagai berikut: 
Tabel 7. Hasil Perhitungan Evapotranspirasi

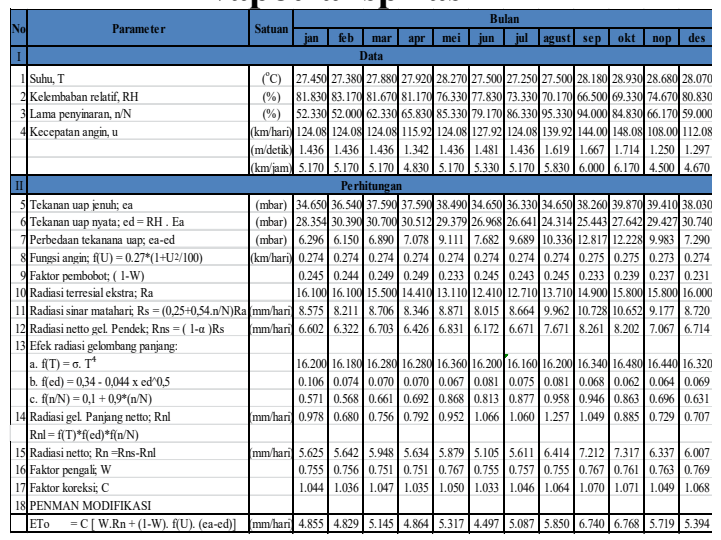

\subsection{Analisa Debit Inflow}

Debit inflow ini digunakan untuk menganalisa kebutuhan irigasi dan daya listrik yang akan dihasilkan di Pembangkit Listrik Tenaga Air (PLTA) Pada analisa debit inflow menggunakan metode FJ Mock sebagai debit andalan.

\section{Tabel 8. Hasil Perhitungan Debit} Andalan

\begin{tabular}{|c|c|c|c|c|c|c|c|c|c|c|c|c|c|}
\hline & tathun & & 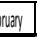 & & & & & & \multicolumn{3}{|c|}{ sentember october } & \multicolumn{2}{|c|}{ hovember december } \\
\hline & 2000 & 234 & 3.93 & 3.19 & 3.00 & 3.09 & 4,58 & 5.04 & 1.08 & 1.53 & 4.57 & 410 & $5 \pi \pi$ \\
\hline & 2002 & 19.45 & 4,34 & 5.58 & 7.49 & & 1.65 & & & & & & \\
\hline & 2003 & 5.93 & 1.49 & 7.21 & 6.94 & 314 & 0.94 & & & & 1.177 & & 3.30 \\
\hline & 2002 & 4.08 & 10.50 & 4.3.1. & 250 & 3.77 & 1.88 & 1.1. & 126 & 1.26 & 2.52 & & 6.65 \\
\hline & 2005 & 3.80 & 9.76 & 10.45 & 5.87 & & 5.22 & & & & 247. & & \\
\hline & 2006 & 8.6. & 8.38 & 6.43 & 6.51 & 377 & 1.59 & 13 & 162 & & 1.79 & & \\
\hline & 2000 & 4.09 & 7.15 & 10000 & 7.27 & 4.03 & 5.94 & 6.64 & 193 & 1.9 & 3.87 & & 7.6. \\
\hline & 2008 & 6.25 & 5.74 & 10.19 & 5.25 & 2.04 & 3.44 & 1.08 & 5.46 & 3.59 & 3.84 & & 9.3 \\
\hline & 2000 & 333 & 4.84 & & 5.56 & & 4.53 & & 1.17 & & 1.28 & & \\
\hline 10] & 2000 & 4.68 & 15.58 & 10.88 & 7.15 & $9.2 .2 x-1$ & 11.75 & & 5.81 & 11 & 9.92 & & 11.1 \\
\hline & & & & & $5.60 \mid$ & & 3.89 & & & & & & \\
\hline
\end{tabular}

Sedangkan kebutuhan irigasi di sana sebesar $26,745 \mathrm{~m}^{3} / \mathrm{dtk}$

\subsection{Perencanaan Pembangkit Listrik Tenaga Air}

PLTA adalah pembangkit listrik yang mengunakan potensi tenaga air dikonversikan menjadi tenaga listrik. Mulamula tenaga air dikonversikan menjadi tenaga mekanik oleh turbin air, kemudian turbin air memutar generator yang membangkitkan tenaga listrik. Dari debit inflow yang ada di waduk di optimalkan sebagai potensial air tanpa mengurangi kebutuhan irigasi yang ada di daerah irigasi waduk klampis. Dengan adanya analisa debit dari debit inflow dan kebutuhan irigasi dapat di tentukan debit daya listrik yang tersedia dan perencanaan komponen Pembangkit Listrik Tenaga Air

Tabel 9. perhitungan debit probabilitas $80 \%$ tiap tahun

\begin{tabular}{|c|c|c|c|c|c|c|c|c|c|c|c|c|c|c|}
\hline tathun & probabilitas & january & february m & ich & & may & jinn. & jully & & gust & September loct & & november Id & ecember \\
\hline 120 & 9167 & 2.34 & 1.49 & 3.19 & 2.5. & & 3.09 & 0.94 & 0.94 & 107 & $\begin{array}{r}1.07 \\
\end{array}$ & 1.17 & 244 & 122 \\
\hline 20 & 83.33 & 3.3.3. & 237 & 3.81 & 3.0. & & 204 & 159 & 1.111 & 108 & 1.17 & 1288 & $2 \pi$ & 22. \\
\hline 20 & 75.00 & 3.80 & 3.93 & 4.31 & 5.22 & & 3.14 & 165 & 130 & 1177 & 1.26 & 179 & 3.06 & 3.30 \\
\hline & 66.67 & 4.08 & 4.34 & 5.58 & 5.2. & & 3.71 & 1888 & 1.36 & 1266. & 1.53 & 207 & 4.10 & 5.70 \\
\hline & 58.33 & 4.09 & 4.84 & 6.01 & 5.5 & & 3.77 & 3.44 & 1.65 & 155 & 1.63 & 231 & 4.42 & 6.65 \\
\hline 20 & 50.00 & 4.68 & 5.74 & 6.43 & 5.8. & & 3.77 & 3.89 & 1.68 & 163 & 1.88 & 247. & 4.600 & 6.72 \\
\hline 20 & 41.67 & 5.76 & 7.15 & 7.21 & 6.5 & & 4.03 & 4.53 & 3.91 & 188 & 1.93 & 252 & 5.36 & 6.85 \\
\hline 20 & 33.33 & 5.93 & 8.38 & 10.19 & 6.9. & & 4.45 & 458 & 5.04 & 1933 & 2.25 & 3.84 & 6.50 & 7.66 \\
\hline 20 & 25.00 & 6.25 & 9.76 & 10.45 & 7.11 & & 9.29 & 5.22 & 6.64 & 5.46 . & 3.00 & 3.87 & 7.61 & 7.7. \\
\hline 10 & 16.67 & 8.61 & 10.50 & 10.88 & 7.22 & & 9.81 & 5.94 & 8.04 & 5.81 & 3.59 & 4.57 & 8.27 & 9.38 \\
\hline 11 & 8.33 & 19.45 & 15.58 & 10.90 & 7.4 .4 & & 10.06 & 1175 & 8.88 & 6.44 & 11.24 & 9.92 & 13.01 & 1116 \\
\hline & atr-rota & 6.21 & 6.73 & 7.18 & 5.7. & & 5.20 & 4.13 & 3.69 & 266 & 2.78 & 3.25 & 5.65 & 6.24 \\
\hline & $807 \%$ & 3.52 & 2.99 & 4.01 & 3.9. & & 2.48 & 1.62 & 1.19 & 1.11 & 1.21 & 148 & 2.89 & \\
\hline
\end{tabular}

Dari hasil di atas tidak memungkinan bahwa debit untuk pembangkit listrik tenaga air di buat rata-rata oleh karena itu perlu adanya permodelan debit turbin dan debit irigasi agar keduanya dapat berjalan bersamaan. Untuk daya turbin sangat di pengaruhi oleh head yang ada, oleh karena itu tinggi muka air harus terjaga tetap pada elevasi tertentu.

Direncanakan mengunakan 2 buah turbin, dimana satu memiliki kapasitas 1 $\mathrm{m}^{3} /$ dtk. Sisa dari dari turbin bisa masuk kedalam jaringan irigasi dan jika berlebih akan di buah ke sungai lagi.

Simulasi debit dapat di lihat pada tabel 10. 
Tabel 10. Perhitungan Simulasi Debit

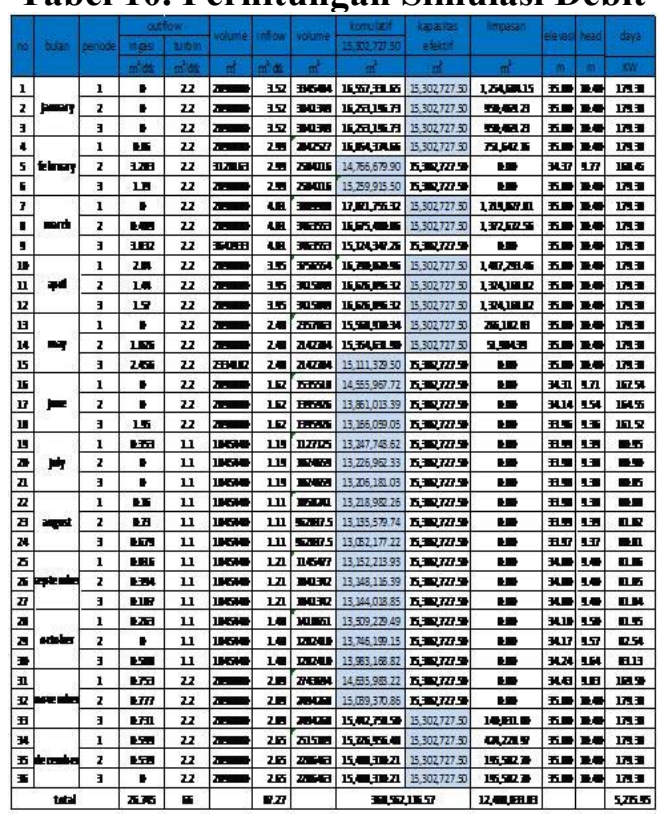

\section{Perhitungan pipa}

Pipa penstock yang di gunakan

a. Perhitungan dimensi penstock

$$
\begin{aligned}
& D=0,72 \times Q^{0.5} \\
& D=0,72 \times\left(1,2 \mathrm{~m}^{3} / d t k\right)^{0.5} \\
& d=0.789 \mathrm{~m}=79 \mathrm{~cm} \\
& \text { Dengan tebal pipa } 4 \mathrm{~mm}
\end{aligned}
$$

b. Perhitungan pipa irigasi

$$
\begin{gathered}
3.3 \frac{m^{3}}{d t k}=\pi 0.25 d x 80 \times(0.25)^{\frac{2}{3}} 0.321^{\frac{1}{2}} \\
d=0.21 \mathrm{~m}=21 \mathrm{~cm}
\end{gathered}
$$

\section{Perhitungan saluran pembuang}

Dimensi saluran pembuang mengunakan debit $2.2 \mathrm{~m}^{3} / \mathrm{dt}$

Maka dimensi saluran di lapangan $\mathrm{b}=1.5 \mathrm{~m}$ maka $\mathrm{h}=0.9 \mathrm{~m}$

\section{Perhitungan kehilangan energi}

\section{1. dari intake}

$h e=1,3 \frac{v^{2}}{2 g}$

$h e=1,3 \frac{(13.47 \mathrm{~m} / d t k)^{2}}{2 \times 9,8}=12.034 \mathrm{~m}$

\section{2. dari penstock}

Untuk pipa tegak lurus

$$
h_{e}=f \times L \frac{V^{2}}{2 g} \times D
$$

Pada pipa penstock 1

$$
\begin{gathered}
h_{e}=0,0028 \times 12.93 \mathrm{~m} \frac{(13.47 \mathrm{~m} / d t k)^{2}}{2 \times 9,8 \mathrm{~m} / d t k^{2}} \times 0.72 \\
=0,24 \mathrm{~m}
\end{gathered}
$$

Pada pipa penstock 2

$$
\begin{gathered}
h_{e}=0,0028 \times 13.91 \mathrm{~m} \frac{(13.47 \mathrm{~m} / d t k)^{2}}{2 \times 9,8 \mathrm{~m} / d t k^{2}} \times 0.72 \\
=0,26 \mathrm{~m}
\end{gathered}
$$

Pada pipa irigasi

$$
\begin{gathered}
h_{e}=0,0028 \times 13.76 \mathrm{~m} \frac{(13.47 \mathrm{~m} / d t k)^{2}}{2 \times 9,8 \mathrm{~m} / d t k^{2}} \times 0.21 \\
=0,07 \mathrm{~m}
\end{gathered}
$$

Untuk belokan pada pipa

Karena sudut belok lebih dari $90^{\circ}$ maka nilai $\mathrm{kb}=1$

$$
\begin{aligned}
& h e=\frac{v^{2}}{2 g} \\
& h e=\frac{13,47^{2}}{2 \times 9,8 \mathrm{~m} / d t k^{2}}=9,25 \mathrm{~m}
\end{aligned}
$$

\section{Pemilihan Jenis Turbin}

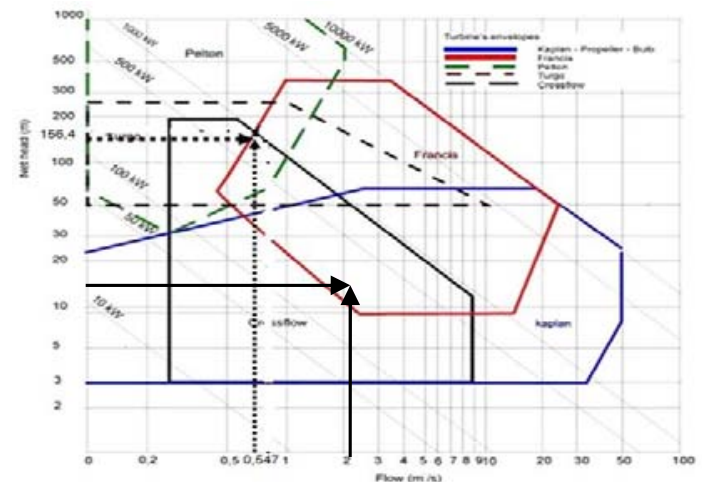

Gambar 5. Grafik Hubungan Head dan Debit untuk penentuan jenis turbin

Turbin yang digunakan jenis Kaplan atau propeller

\section{KESIMPULAN DAN SARAN}

\subsection{Kesimpulan}

Dari hasil analisa dan perhitungan yang telah dilakukan, maka didapat kesimpulan bawah :

1. Dari hasil exisiting waduk dan waduk setelah redesain 
- Dari hasil volume effektif waduk existing sebesar 4.994.361,52 $\mathrm{m}^{3}$.

- Dan dari analisa tampungan efektif waduk diperoleh volume sebesar $17.957 .957 \mathrm{~m}^{3}$. Volume dead storage $415.000,75 \mathrm{~m}^{3}$ dan kapasitas efektif 15.302.727,5 $\mathrm{m}^{3}$

2. Dari analisa debit banjir dan debit andalan di dapat

Debit banjir

- curah hujan rencana dipilih distribusi hujan log pearson type III dengan periode ulang 1000 tahun sebesar 280,907 $\mathrm{mm}$

- Dari analisa debit banjir dengan metode unit hidrograf Nakayasu dieperoleh 1098,146 m³/detik

Debit andalan

- Dari hasil evapotranspirasi metode penma modifikasi.di peroleh total setahun evapotranspirasi sebesar 65,062 $\mathrm{mm}$.

- Dari hasil debit andalan 80\% di atas diperoleh debit total dalam setahun sebesar $29,04 \mathrm{~m}^{3} / \mathrm{dtk}$

3. Dari analisa untuk perencanaan bendungan di dapat

- Dari analisa penelusaran debit banjir di dapat debit outflow $526.89 \mathrm{~m}^{3} / \mathrm{dtk}$ dan tinggi muka air di atas mercu setinggi 2,84 $\mathrm{m}$

- bendungan direncanakan dengan lebar bendungan $50 \mathrm{~m}$, tinggi bendungan 19,38 m.dan panjang spillway $12.5305 \mathrm{~m}$

4. Dari analisa perhitungan, di dapat perencanaan perencanaan bangunan Pembangkit Listrik Tenaga Air(PLTA) di dapat

- Perencanaan turbin yang digunakan dengan metode simulasi debit dan head direncanakan menggunakan 2 turbin dengan kapasitas 1 turbin $1,1 \mathrm{~m}^{3} / \mathrm{dtk}$

- dimensi intake $2 \mathrm{~m} \times 2 \mathrm{~m}$

- Volume kolam penanang sebesar $95,52 \mathrm{~m}^{3}$

- Pipa penstock di rencanakan dengan diameter $79 \mathrm{~cm}$ dengan tebal $4 \mathrm{~mm}$

- Saluran pembuang dengan dimensi lebar $1.5 \mathrm{~m}$ dan tinggi air $0,9 \mathrm{~m}$

- Dari analisa simulasi debit dapat di peroleh energi listrik yang di hasilkan sebesar 1.259.757 KwH

\subsection{Saran}

Setelah mendesain waduk klampis, maka ada beberapa hal yang di gunakan untuk lebih mengoptimalkan debit turbin dan daya yang di hasilkan sebagai berikut :

1. Meninggikan head lebih tinggi

2. Debit inflow di alih fungsikan dari semula digunakan irigasi dan pembangkit listrik tenaga air menjadi pembangkit listrik tenaga air saja

\section{DAFTAR PUSTAKA}

[1] Anggrahini. 2005.Hidrolika Saluran Terbuka.Surabaya: Srikandi

[2] Hadisusanto,Nugroho. 2011. Aplikasi Hidrologi. Jakarta : Jogja Mediautama.

[3] Patty, O.F. 1995. Tenaga Air. Erlangga, Jakarta.

[4] Soedibyo.2003.Teknik Bendungan.Pradnya Paramita, Jakarta

[5] Soemarto,C.D. 1999. Hidrologi Teknik. Jakarta : Erlangga.

[6] Sosrodarsono,Suyono. 1981. Bendungan Type Urugan. Jakarta: P.T. Pradnya Paramita.

[7] Sosrodarsono,Suyono. 1983. Hidrologi untuk Pengairan. Jakarta: P.T. Pradnya Paramita.

[8] Studi Kelayakan dan Penyusunan Basic Design Proyek PLTA Siteki, Volume I

[9] Bab 3 "Parameter Design Optimum. 
Halaman ini sengaja dikosongkan

Hal 66 